\title{
A youth empowerment intervention to prevent childhood obesity: design and methods for a cluster randomized trial of the $\mathrm{H}_{2} \mathrm{GO}$ ! program
}

Monica L. Wang ${ }^{1,2,3^{*}}$ (D), Linda S. Sprague Martinez ${ }^{4,5}$, Janice Weinberg ${ }^{6}$, Selenne Alatorre ${ }^{1}$ Stephenie C. Lemon ${ }^{7}$ and Milagros C. Rosal ${ }^{7}$

\begin{abstract}
Background: Reducing sugar-sweetened beverage (SSB) consumption is a promising dietary target for childhood obesity prevention. This paper describes the design and methods of a cluster randomized trial of $\mathrm{H}_{2} \mathrm{GO}$ !, a youth empowerment intervention to prevent childhood obesity through reducing SSB consumption among a lowincome, ethnically diverse sample of youth.

Methods: This cluster randomized controlled trial is an academic-community partnership with the Massachusetts Alliance of Boys and Girls Clubs (BGC). Ten BGC sites will be randomly assigned to the $\mathrm{H}_{2} \mathrm{GO}$ ! intervention or a waitlist, usual care control. Eligible study participants will be $N=450$ parent-child pairs (youth ages 9-12 years and their parents/caregivers) recruited from participating BGCs. The 6-week in-person $\mathrm{H}_{2} \mathrm{GO}$ ! intervention consists of 12 group-based sessions delivered by BGC staff and youth-led activities. An innovative feature of the intervention is the development of youth-produced narratives as a strategy to facilitate youth empowerment and parental engagement. Child outcomes include measured body mass index z scores (zBMI), beverage intake, and youth empowerment. Parent outcomes include beverage intake and availability of SSBs at home. Outcomes will be measured at baseline and at 2, 6, and 12 months. With a 75\% retention rate, the study is powered to detect a minimum group difference of 0.1 zBMI units over 12 months.
\end{abstract}

Discussion: Empowering youth may be a promising intervention approach to prevent childhood obesity through reducing SSB consumption. This intervention was designed to be delivered through BGCs and is hypothesized to be efficacious, relevant, and acceptable for the target population of low-income and ethnically diverse youth.

Trial registration: ClinicalTrials.gov NCT04265794. Registered 11 February 2020.

Keywords: Childhood obesity, Youth empowerment, Cluster randomized trial, Sugar-sweetened beverage consumption, Design and methods

\footnotetext{
* Correspondence: mlwang@bu.edu

'Department of Community Health Sciences, Boston University School of Public Health, 801 Massachusetts Avenue, Boston, MA 02118, USA

${ }^{2}$ Office of Narrative, Boston University Center for Antiracist Research, Boston, MA 02215, USA

Full list of author information is available at the end of the article
}

(c) The Author(s). 2021 Open Access This article is licensed under a Creative Commons Attribution 4.0 International License, which permits use, sharing, adaptation, distribution and reproduction in any medium or format, as long as you give appropriate credit to the original author(s) and the source, provide a link to the Creative Commons licence, and indicate if changes were made. The images or other third party material in this article are included in the article's Creative Commons licence, unless indicated otherwise in a credit line to the material. If material is not included in the article's Creative Commons licence and your intended use is not permitted by statutory regulation or exceeds the permitted use, you will need to obtain permission directly from the copyright holder. To view a copy of this licence, visit http://creativecommons.org/licenses/by/4.0/. The Creative Commons Public Domain Dedication waiver (http://creativecommons.org/publicdomain/zero/1.0/) applies to the data made available in this article, unless otherwise stated in a credit line to the data. 


\section{Background}

Over one third of U.S. school-age children are overweight or obese $[1,2]$ and at risk for diabetes, heart disease, and shorter life expectancies [3]. Reducing sugarsweetened beverage (SSB) intake is a high-impact dietary target for obesity prevention, particularly among lowincome youth and youth of color who have persistently higher SSB intake and obesity risk [4-6]. Data from the 2013-2014 National Health and Nutrition Examination Survey (NHANES) indicate that $63.5 \%$ of youth ages $6-$ 11 years consumed $\geq 1$ SSBs on a given day [7], with considerably higher SSB intake among low-income youth and Hispanic and non-Hispanic Black youth [4, 5, 7-9]. Low-income youth are also more likely to be heavy SSB consumers ( $\geq 500 \mathrm{kcals} /$ day) than higher-income youth $[9,10]$. Reducing SSB intake can lead to $8-11 \%$ reduction in energy intake among youth [4, 11-15]. Efficacious strategies to reduce SSB intake are therefore needed, particularly among low-income youth and youth of color who are high SSB consumers.

Empowerment approaches hold potential for catalzying positive behavior change in childhood obesity intervention contexts by building youth's capacity to affect change in their lives and in the broader community [16, 17]. Empowerment-based health interventions seek to improve health behaviors and outcomes, particularly among low-income populations and communities of color, by helping individuals develop an ecological understanding of health and identify strategies for change that are relevant in the context of their lived experiences $[18,19]$. There is growing body of evidence that indicates empowerment may mediate behavior change and obesity-related outcomes among youth [16, 17, 20, 21]. Prior youth empowerment interventions have demonstrated small improvements in diet, physical activity, and BMI among youth [22-24], though few have utilized rigorous study designs or examined empowerment as a mediator of intervention effects.

Cultivating youth narratives or stories is one empowerment strategy that may facilitate empowerment and health behavior change among youth of color [2528]. Unlike traditional didactic approaches, the development of narratives within an empowerment framework engages youth in a transformative process by recognizing knowledge embedded within their personal stories and encouraging youth to take action $[19,29,30]$. The creation and sharing of narratives thus facilitates empowerment through elaborate message processing and personalization [27]. The use of narratives within other health interventions has shown success in behavior change, including improved diet, among adults [31-35]. Results from our pilot site-randomized study of $N=100$ parent-child pairs indicated that our narrative-based youth empowerment SSB intervention $\left(\mathrm{H}_{2} \mathrm{GO}\right.$ !) was associated with 6-month reductions in child zBMI and 6-month reductions in SSB intake and increases in water intake among children and parents [36].

The goals of this study are to test the efficacy of $\mathrm{H}_{2} \mathrm{GO}$ ! among an ethnically diverse sample of youth through a cluster randomized controlled trial (parallel group) and measure empowerment as a mediator. We partnered with Massachusetts Allianc of Boys and Girls Clubs of America (BGCs) to develop and pilot test $\mathrm{H}_{2} \mathrm{GO}$ ! [37]. BGCs are an ideal partner for this proposal due to their commitment to empowering youth to lead healthy lives and their potential to reach large segments of our target population (4 million school-age youth; $56 \%$ low-income) nationally. We hypothesize that child participants in the intervention sites will have reduced zBMI and reduced SSB intake compared to child participants in the comparison sites and that the intervention effect(s) will be mediated by youth empowerment. This paper describes the design and methods for the cluster randomized controlled trial of the $\mathrm{H}_{2} \mathrm{GO}$ ! intervention.

\section{Methods/design \\ Theoretical foundation}

Our study applies Empowerment Theory (ET) [38] through intervention conceptualization, implementation, and measurement. Youth become empowered (e.g., gain mastery over their lives) as they develop critical consciousness, which occurs as they begin to fully understand the factors that shape their environment and in turn their behavior [39]. ET posits that youth empowerment occurs through three interrelated components or processes: 1) intrapersonal (development of youth beliefs, such as confidence and sense of agency to make a difference); 2) interactional (cultivation of critical awareness and critical thinking skills to help youth become independent decision makers and create situations aligned with their goals); and 3) behavioral (provision of opportunities for youth to practice skills in real life contexts and to take action to produce desired changes in their communities) [17]. Our intervention was developed for early and pre-adolescent youth ages 9-12 years, as children under 9 may not have the concrete operational development [40] needed for skills targeted in an empowerment intervention. The $\mathrm{H}_{2} \mathrm{GO}$ ! intervention integrates the three ET processes to target SSB intake among youth through BGC staff-led sessions and youthled activities (Fig. 1).

\section{Study setting and population}

$\mathrm{BGC}$ is a national organization that provides affordable after-school programs for over 4 million school-aged youth (29\% White, 27\% Black, 24\% Latino) across 4300 sites nationwide [41]. BGCs are an ideal community partner for youth empowerment interventions due to 

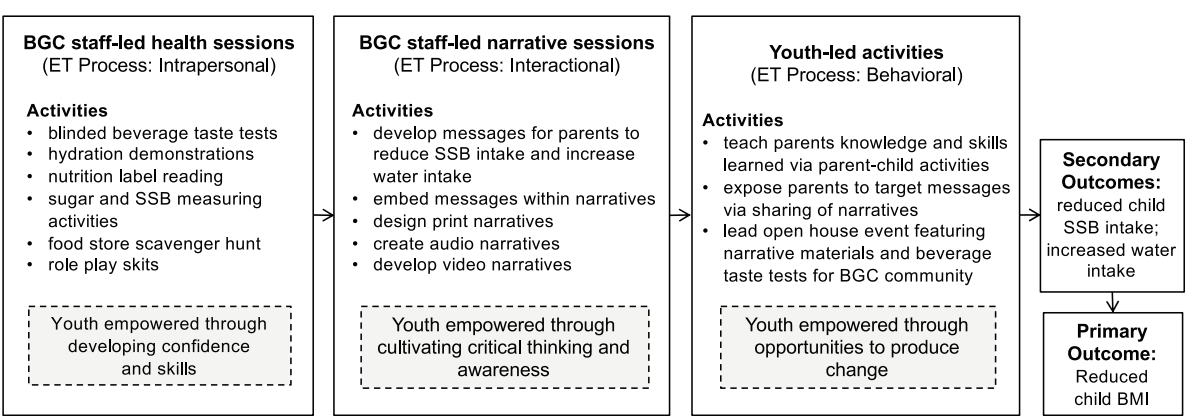

Fig. 1 Intervention Conceptual Model by Empowerment Theory (ET) Processes

their commitment to youth empowerment and health promotion [42-48]. BGC sites will be recruited from the 40 BGC sites in Massachusetts, USA and selected for comparability in enrollment size and ethnic composition.

Parent-child pairs will be screened, recruited, and consented by study staff from participating BGC sites via inperson, phone, or web-based modalities. Study staff will obtain parental permission and verbal assent through three main ways: 1) verbal parental permission and verbal child assent in-person in the BGC setting; 2) verbal parental permission and verbal child assent over the phone using a REDCap form (completed and documented by study staff); and 3) online form using REDCap documenting parental permission and verbal child assent. Child inclusion criteria are: ages 9-12 years; current member at the BGC study site; able to understand and communicate in English; able and willing to provide consent; parental/caregiver permission to participate; has access to a wifi-enabled device at home (to allow for study participants to continue with intervention participation in the event the intervention needs to transition to online delivery due to COVID-19); and no medical condition that limits ability to change beverage consumption behaviors. Parental/caregiver inclusion criteria are: parent/caregiver to a BGC child member; 18 years or older; able to understand and communicate in English; able and willing to provide consent; and no medical condition that limits ability to change beverage consumption behaviors.

\section{Study design}

This study is an unblinded parallel-group cluster randomized controlled trial with $N=10 \mathrm{BGC}$ sites randomized to the intervention or comparison status. Geographic location is used as a stratification variable; sites within each stratum are spaced $>5$ miles apart to minimize contamination bias. One site within each stratum will be randomly assigned to the intervention and the other to a wait-list, usual care condition. The randomization will be conducted by the project statistician using computer-generated random numbers. We opted to use a stratified sampling scheme to increase balance of BGC characteristics between study arms and include a representative sample of BGCs to increase generalizability.

After sites are randomized, participants will undergo recruitment and enrollment and complete in-person study assessments at baseline, 2, 6, and 12 months follow-up (see Fig. 2). Comparison group participants will have study assessments scheduled to match the timing of each intervention cycle. To enhance adherence to intervention protocols, the study team will complete intervention fidelity and process measures of intervention sessions using intervention attendance, recruitment, and retention rates, as well as an intervention fidelity checklist to score completion of intervention activities $(0=$ did not do this activity; $1=$ partially completed; $2=$ completed) across each of the 12 intervention sessions. The study team will also monitor intervention sessions and provide corrective feedback and ongoing trainings and refresher sessions as needed. Intervention fidelity monitoring and corrective feedback processes will be completed remotely via Zoom when study staff were unable to be present onsite BGC due to COVID-19 restrictions.

Study protocol and procedures, including adapatations and alternative plans that accommodated for COVID-19 restrictions and guidance for in-person and indoor activities, were approved by the Boston University Medical Center Institutional Review Board (protocol \#H-39841). Any important protocol modifications will be communicated and approved by the investigators, the IRB, trial participants, the trial registry, and the study sponsor.

\section{Intervention development}

The $\mathrm{H}_{2} \mathrm{GO}$ ! intervention was designed to reduce SSB intake (recommended guideline of $0 \mathrm{SSBs} /$ day) and promote replacing SSBs with water (recommended guideline of 5-8 cups/day) among 9-12 year old youth and their parents. Intervention materials, strategies, format, and content were previously pre-tested and refined 


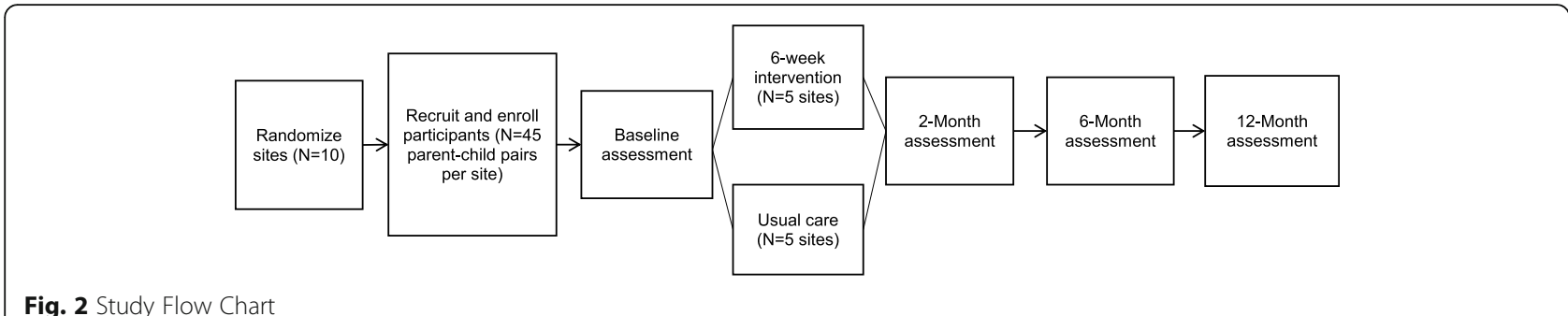

Fig. 2 Study Flow Chart

based on youth, parent, and staff feedback and study staff observations on intervention feasibility, acceptability, and engagement in our pilot study [36, 37]. To prepare for the event that part or all of the intervention may need to be delivered remotely, the study team developed virtual curriculum content and activities (designed to be delivered via Zoom) to parallel the inperson activities. Study staff will train BGC staff to deliver the intervention through a remote-based initial training followed by quarterly booster sessions; this training will review curriculum and protocols for each intervention session through an intervention manual, provide practice of protocol implementation, and include delivery of feedback during mock sessions.

\section{Intervention condition}

The 6-week intervention consists of 12 group-based weekly in-person sessions (1-h sessions twice a week) delivered by trained BGC program staff to BGC child study participants in the BGC setting during regular BGC hours (after-school on weekdays) and a culminating BGC community open house event for all youth and parent members. Intervention activities consist of three main components mapped onto the three ET processes:
1. BGC staff-led health sessions for youth (intrapersonal): Youth will participate in weekly groupbased interactive health sessions delivered by trained BGC staff. The primary objectives are to decrease SSB intake among youth and to promote water intake. Strategies to lead knowledge, confidence, and skill building activities targeting children's SSB consumption have been previously pilottested in our study population (see Table 1 for session topics).

2. BGC staff-led narrative sessions for youth (interactional): Youth will be guided by BGC staff to produce narratives featuring behavioral messages on beverage intake, applying knowledge and skills acquired from the health sessions. Narrative materials will build upon youth's lived experiences, consist of youth's own stories, and be developed by youth through a variety of mediums (e.g., print, audio, video). Staff will use pictorial-based analysis methods (e.g., SHOWed) to guide youth to critically reflect on narratives created [49].

3. Youth-led activities empowering youth as change agents (behavioral): Youth will engage parents in critical dialogues by teaching parents knowledge and skills learned through weekly take-

Table 1 Sample $\mathrm{H}_{2} \mathrm{GO}$ ! Pilot Intervention Session Topics and Activities

\begin{tabular}{|c|c|c|}
\hline $\begin{array}{l}\text { Weekly BGC-staff led health sessions Intraper- } \\
\text { sonal (building confidence and skills) }\end{array}$ & $\begin{array}{l}\text { Weekly BGC-staff led narrative } \\
\text { sessions } \\
\text { Interactional (critical thinking) }\end{array}$ & $\begin{array}{l}\text { Weekly youth-led activities } \\
\text { Behavioral (organized youth action) }\end{array}$ \\
\hline $\begin{array}{l}\text { 1. Water is Good for You! } \\
\text { (hydration demonstration) }\end{array}$ & $\begin{array}{l}\text { Develop print narratives to } \\
\text { promote water intake }\end{array}$ & \multirow{6}{*}{$\begin{array}{l}\text { Teach parents information and skills learned through } \\
\text { parallel weekly parent-child activities } \\
\text { Engage parents in critical dialogues on target behavioral } \\
\text { messages through weekly sharing of narratives }\end{array}$} \\
\hline $\begin{array}{l}\text { 2. Re-Think Your Drink (blinded taste tests of } \\
\text { flavored water) }\end{array}$ & $\begin{array}{l}\text { Develop print narratives to } \\
\text { encourage non-SSB alternatives }\end{array}$ & \\
\hline $\begin{array}{l}\text { 3. Find the Facts } \\
\text { (label reading, SSB measuring activity) }\end{array}$ & $\begin{array}{l}\text { Develop print narratives to explain } \\
\text { how to identify SSBS }\end{array}$ & \\
\hline $\begin{array}{l}\text { 4. Explore the Corner Store (scavenger hunt of SSBS } \\
\text { and non-SSBS) }\end{array}$ & $\begin{array}{l}\text { Develop audio narratives to } \\
\text { explain how to identify SSBS }\end{array}$ & \\
\hline $\begin{array}{l}\text { 5. Water, Water, Everywhere } \\
\text { (role play skits to find ways to drink water) }\end{array}$ & $\begin{array}{l}\text { Develop video narratives to find } \\
\text { opportunities to drink water }\end{array}$ & \\
\hline $\begin{array}{l}\text { 6. SSB Triggers } \\
\text { (role play skits to manage SSB triggers }\end{array}$ & $\begin{array}{l}\text { Develop video narratives to } \\
\text { manage SSB triggers }\end{array}$ & \\
\hline
\end{tabular}

Culminating youth-led BGC community event featuring display of narratives and flavored water taste tests Behavioral (organized youth action) 
home activities and sharing of narrative materials produced, culminating in a youth-led BGC community event that will include a display of narrative materials through an art gallery format; live youth performances, a viewing of finalized narratives, and youth-led taste tests of non-sweetened beverages.

Child participants will also receive a reusable water bottle and a pictorial intervention booklet developed by the research team, which includes intervention activity worksheets, parent-child take-home activities, and beverage consumption tracking and goal-setting sheets. Activity worksheets will be completed by participants during intervention sessions, and parent-child take-home activities will be completed following each session. Sample session topics and activities are summarized in Table 1. Additional details on intervention strategies and intervention session activities have been previously described $[36,37]$.

\section{Comparison condition}

Parent-child pairs in comparison sites will receive usual care (standard BGC programming) during the study and the intervention upon study completion. BGCs deliver health and life skills programs each year on a variety of topics determined by each site (e.g., cyber-safety, substance use prevention). Comparison sites will continue to implement such programs but will refrain from implementing obesity-specific programs. Upon completion of data collection, the study team will train BGC staff in comparison sites to deliver the $\mathrm{H}_{2} \mathrm{GO}$ ! intervention and provide intervention toolkits and protocols.

\section{Measures \\ Primary outcome}

The primary outcome is change in child zBMI (number of standard deviations by which a child differs from the mean BMI of children of the same age and sex) over 12 months, an appropriate measure of that allows for comparing children of different ages over time as they grow [50]. Children's height and weight will be used to calculate BMI, age- and sex-specific BMI percentiles, zBMI, and standard BMI-based weight status categories using CDC growth charts [51]. Trained BGC and study staff will take the average of two measurements of children's height and weight using a stadiometer and a medical quality scale, respectively. Children will be measured in a private setting wearing light clothing (e.g., without shoes and heavy outer layers). Secondary outcomes and covariates for parent and child participants are summarized in Table 2 and are based upon validated instruments and surveys [52-61].

Table 2 Secondary Outcome and Covariate Measures

\begin{tabular}{|c|c|}
\hline \multicolumn{2}{|l|}{ Child Outcomes (self-report) } \\
\hline $\begin{array}{l}\text { SSB and water consumption } \\
\text { (secondary outcomes) }\end{array}$ & $\begin{array}{l}\text { A } 15 \text {-item beverage intake questionnaire (BEVQ) will be used to assess frequency and amount of SSB and } \\
\text { water consumption and energy intake (kcalories) from SSBs. The BEVQ has demonstrated reliability and valid- } \\
\text { ity in assessing beverage intake against } 24-\mathrm{h} \text { recalls among youth [52]. }\end{array}$ \\
\hline Beverage intake self-efficacy & $\begin{array}{l}\text { Self-efficacy to reduce SSB intake and increase water intake will be assessed using items from a nutrition self- } \\
\text { efficacy scale validated among youth ages } 8-11 \text { years [53]. }\end{array}$ \\
\hline Diet & $\begin{array}{l}\text { Frequency of consuming specific foods/food groups (e.g., vegetables, fruits, fast food, desserts) will be } \\
\text { assessed using items from the School Physical Activity and Nutrition (SPAN) monitoring system [54]. These } \\
\text { items have been validated for use by children in grades } 4 \text { and higher and were selected for their brevity and } \\
\text { low response burden. }\end{array}$ \\
\hline Physical activity & $\begin{array}{l}\text { Time spent outdoors [55] and number of days during the past week children participated in } \geq 60 \text { min of } \\
\text { moderate-to-vigorous physical activity [56] will be used to assess child physical activity. }\end{array}$ \\
\hline Screen time & $\begin{array}{l}\text { Hours/day watching TV away from school (on TV or through a mobile or computer device) and hours/day } \\
\text { playing video or computer games or using a computer for something other than schoolwork (including time } \\
\text { on the Internet, instant messaging) away from school [54] will be used to assess screen time. }\end{array}$ \\
\hline Youth empowerment & $\begin{array}{l}\text { The 8-item Sociopolitical Control Scale for Youth (SPCS-Y) [57], which has been validated as a measure of } \\
\text { empowerment among urban youth [58], will be used to assess youth empowerment. The SPCS-Y uses a 10- } \\
\text { point, phrase completion response format and consists of a leadership/competence subscale and a policy/so- } \\
\text { cial control subscale [59]. }\end{array}$ \\
\hline Socio-demographics & Child gender, age, and race/ethnicity will be assessed via brief survey items. \\
\hline \multicolumn{2}{|l|}{ Parent Outcomes (self-report) } \\
\hline SSB and water consumption & $\begin{array}{l}\text { Items from the beverage intake questionnaire (BEVQ-15) [60] assessing frequency and amount of beverages } \\
\text { consumed will be used to assess SSB and water intake and SSB energy intake. The BEVQ-15 has been vali- } \\
\text { dated against 24-h dietary recalls among adults, including low-literacy populations [60]. }\end{array}$ \\
\hline Home SSB availability & $\begin{array}{l}\text { One survey item assessing how often SSBS are available at home (5-point Likert scale ranging from "never" to } \\
\text { "always") [61] will be used to measure SSB home availability. }\end{array}$ \\
\hline Socio-demographics & $\begin{array}{l}\text { Gender, age, race/ethnicity, education, income, occupation, and child eligibility for free/reduced priced lunch } \\
\text { will be assessed via survey items. }\end{array}$ \\
\hline
\end{tabular}




\section{Statistical approach and power}

Our sample size calculations ( $N=45$ parent-child pairs per each of the 10 sites) are based on the primary hypothesis that child participants in intervention sites will have reduced zBMI compared to child participants in comparison sites over 12 months. Our pilot study showed an effect size of 0.22 zBMI units over 6 months [36]. We powered our analysis to detect a minimum effect size of 0.1 units over 12 months (a conservative approach considering possible attenuation of effects over the doubling of study time period) and anticipate a 0.15 SD in both groups. A 0.1 effect size is reasonable for populations inclusive of healthy weight children; of studies targeting school-aged children including those of healthy weight, randomized SSB interventions have yielded $0.0-0.13$ unit differences in zBMI over $12-18$ months $[62,63]$, and childhood obesity prevention interventions have yielded $0.10-0.16$ unit differences in zBMI over 12 months $[64,65]$. We assume an intra-class correlation coefficient of 0.05 [66-68]. With $\alpha=0.05$ and a $75 \%$ retention rate, we can detect $\geq 0.1$ unit difference in zBMI with over $80 \%$ power and 0.2 unit difference with over $90 \%$ power by enrolling a total of 450 parent-child pair participants.

\section{Recruitment and retention}

We will utilize the following participant recruitment approaches previously tested in our pilot study (identify eligible child participants through the BGC electronic enrollment record system and in collaboration with BGC staff), which yielded $>95 \%$ recruitment rate in our pilot study. Proposed strategies to retain participants include collecting multiple forms of contact information from parent/caregiver participants at baseline, scheduling pre-determined study assessments at dates/times convenient for participants, providing options for online or phone follow-up assessments, implementing a tracking and reminder system, offering assistance and support for participating in study assessments, using email and social media contact approaches, and providing incentives of $\$ 20$ gift cards per assessment.

\section{Data management and confidentiality}

A number of procedures will be utilized to maximize data integrity and quality control procedures for data collection and data entry. Quality control measures implemented by the project data analysists will include detailed and unabmigious specifications for completion of each of the data collection forms, including rules for coding skipped questions, missing data, and/or refusals. Interim incremental data reviews will be performed on all data to compare data collectors and determine variations among observers in responses to questions on data forms. Computer algorithms will be written to check logic and identify internal inconsistencies.

Password-protected study databases and locked offices will be used to maintain data security to the highest extent possible. The key to identification of subjects will be kept in a separate and secure location. These data will be stored and managed on a secure server in a HIPAAcompliant data center with daily back-up. Data entry will be through the REDCapTM Data Capture System (Vanderbilt University). All databases and analytic files will be contained within the Biostatistics and Epidemiology Data Analytics Center (BEDAC) secure environment with access controlled through user-specific login and passwords.

\section{Planned statistical analysis}

Distributions, descriptive statistics, and missing values will be examined for child zBMI. Bivariate analyses will compare intervention and comparison group characteristics using chi-square tests for categorical variables and t-tests for continuous variables. Any statistically notable $(p<0.1)$ imbalances that arise between groups will be adjusted for in multivariable analyses. Analyses will utilize an intent-to-treat approach, with each participant enrolled in the intervention site analyzed as part of the group.

To test our primary hypothesis that children in intervention sites will have decreased zBMI compared to children in comparison sites, we will apply generalized linear mixed models. The hierarchical structure of the data (repeated measures on youth nested within sites) will be modeled by including participant- and site-level random intercepts. A more complex covariance structure for repeated measures over time on participants (e.g. unstructured covariance) will be incorporated into the analysis if necessary. The main predictors of the model include study condition (intervention vs. control), all time points, and the interaction term between study condition and time points. Intervention effects will be evaluated over the entire study period by testing the interaction term of time and study condition, and by specifically comparing change from baseline to 12 months via a statistical contrast. We will also compare changes from baseline to earlier time points using this approach. Covariates associated with child zBMI (e.g., gender, race, other dietary intake, physical activity) will be examined for balance between groups and incorporated into multivariable analyses if imbalances $(p<0.1)$ occur. Potential moderating effects of gender, age, and race/ethnicity on intervention effects will be examined via a three-way interaction with the moderator, the study condition indicator and time. Should significant interaction terms emerge from the data, we will analyze and report intervention effects by appropriate subgroups 
(e.g., males vs. females). Participants with incomplete follow-up can be included in analyses, which are valid under a missing at random assumption. We will assess the likelihood of nonignorable missing data using a pattern mixture model.

To test our secondary hypothesis that children in intervention sites will have decreased SSB intake and increased water intake than children in control sites over 12 months, we propose to compare SSB and water intake using linear mixed models and similar approaches described in the primary hypothesis testing. Comparisons of group mean changes from baseline to 2 and 6 months will also utilize this approach. We will additionally examine changes in child self-efficacy, parental beverage intake, SSB home availability, and spontaneous changes in other BMI-related behaviors (other dietary intake, physical activity, screen time, sleep) over time and by study condition using methods described above. Finally, for our mediation hypothesis, we will first examine whether the pattern of change in youth empowerment over time differs by study condition via a statistical interaction using a linear mixed model. Next, we will examine whether patterns of change over time in primary and secondary outcomes depend on level of empowerment by incorporating an empowerment by time interaction. Finally, we will incorporate both interaction terms (study condition by time and empowerment by time) to determine if the intervention effect is partially or fully mediated by empowerment.

\section{Data safety monitoring board}

Given the minimal risk involved, a full Data and Safety Monitoring Board was not deemed necessary. The PI and project team will be involved in ongoing monitoring of the trial and will meet annually to review study progress, data quality and safety.

\section{Dissemination plan}

We plan to engage past study participants and community members in a series of community presentations regarding study results. We will post results in our project website, including study description, briefs with findings, and publications, as well as share findings to BGCs via newsletters, social media outreach, and local, regional, and/or national presentations. If the intervention is shown to be efficacious, we plan to create a dissemination package for our community partners that includes: manuals describing intervention components; procedures and resources for implementation and evaluation; staff training modules; and information regarding intervention feasibility and acceptability to inform adoption. Within the broader scientific community, we plan to submit study findings for presentation at national conferences and to publish study results in relevant peer-reviewed journals.

\section{Discussion}

Reducing SSB intake is a critical target (and one of many needed) for childhood obesity prevention. The $\mathrm{H}_{2} \mathrm{GO}$ ! intervention targets SSB intake through youth-produced narratives as a strategy to facilitate youth empowerment and parental engagement. The result is a novel SSB intervention that strategically engages youth in developing confidence, skills, and opportunities to affect their broader circumstances through cultivating and sharing their stories in the family and community settings. Our study also aims to measure youth empowerment as a mediator in the context of a childhood obesity prevention trial. Establishing this association will build further evidence of utilizing youth empowerment strategies to improve obesity-related behaviors and outcomes among youth.

We partnered with BGCs, a system of affordable afterschool care that reaches our target population (56\% lowincome; 33\% White, 30\% Black, 23\% Hispanic) nationally [42]. BGCs are an ideal setting and leverage point for childhood obesity prevention programs, given that SSB intake and childhood obesity are major problems that have yet to be sufficiently addressed in this population and setting. The $\mathrm{H}_{2} \mathrm{GO}$ ! intervention was designed in collaboration with BGCs for implementation through BGCs, a setting that has national reach and infrastructure to support our intervention model. The resulting $\mathrm{H}_{2} \mathrm{GO}$ ! intervention aligns with the BGC goal of empowering youth to lead healthy lifestyles and has high potential for sustainability and dissemination.

\section{Abbreviations}

BMl: Body mass index; BGC: Boys and Girls Clubs of America; ET: EmpowermentTheory; SSB: Sugar-sweetened beverages; zBMI: Body mass index z score

\section{Supplementary Information}

The online version contains supplementary material available at https://doi. org/10.1186/s12889-021-11660-5.

Additional file 1.

Additional file 2.

Acknowledgments

The authors would like to acknowledge Jennifer Aldworth and the Massachusetts Alliance of Boys and Girls Clubs as dedicated community partners, the staff and study participants at the Boys and Girls Club of Worcester, Lawrence, and Lowell for their critical input, support and guidance in informing study procedures and materials, our research team members Chloe Miller, Cindy Lee, and Martha Koenig.

Authors' contributions

MW conceived of the study and research question and developed intervention materials. MW and SA drafted the manuscript. MR and SL participated in the design of the study. JW planned the statistical analyses. 
LSM, JW, SA, SL, and MR provided critical revisions for intellectual content. All authors read and approved the final manuscript.

\section{Funding}

This study is funded by the National Institutes of Health $(\mathrm{NIH})$ National Institute of Diabetes and Digestive and Kidney Diseases (NIDDK) Grant \# R01DK120713-01A1 (PI: Wang). Email: NIDDK Health Information Center email: healthinfo@niddk.nih.gov. MW, LSM, JW, SL, and MR are supported by NIDDK Grant \# R01DK120713-01A1. JW is additionally supported by NIH, National Center for Complementary and Integrative Health Grant \# 1UG3AT010621-01 and NIH, National Center for Advancing Translational Sciences Grant \#1UL1TR001430. The study funder did not have any role, nor will they have ultimate authority over any of the following activities: study design, collection, analysis, or interpretation of data; writing the report; the decision to submit the report for publication. The content of this manuscript is solely the responsibility of the authors and does not necessarily represent the views of the $\mathrm{NIH}$.

\section{Availability of data and materials} Not applicable.

\section{Declarations}

\section{Ethics approval and consent to participate}

Verbal parental permission and verbal child assent will be obtained from study participants; all study protocol and procedures including consent processes were approved by the Boston University Medical Center Institutional Review Board (Protocol \#H-39841).

\section{Consent for publication}

Not applicable.

\section{Competing interests}

The authors declare that they have no competing interests.

\section{Author details}

'Department of Community Health Sciences, Boston University School of Public Health, 801 Massachusetts Avenue, Boston, MA 02118, USA. ${ }^{2}$ Office of Narrative, Boston University Center for Antiracist Research, Boston, MA 02215, USA. ${ }^{3}$ Department of Health Policy and Management, Harvard T.H. Chan School of Public Health, Boston, MA 02215, USA. ${ }^{4}$ Macro Department, Boston University School of Social Work, 264 Bay State Rd, Boston, MA 02215, USA. ${ }^{5}$ Center for Social Work Innovation in Health, Boston University School of Social Work, 801 Massachusetts Avenue, Boston, MA 02118, USA. ${ }^{6}$ Department of Biostatistics, Boston University School of Public Health, 801 Massachusetts Avenue, Boston, MA 02118, USA. ${ }^{7}$ Division of Preventive and Behavioral Medicine, Department of Population and Quantitative Health Sciences, University of Massachusetts Medical School, 368 Plantation St, Worcester, MA 01655, USA.

\section{Received: 19 August 2021 Accepted: 25 August 2021}

Published online: 15 September 2021

\section{References}

1. Ogden CL, Carroll MD, Lawman HG, Fryar CD, Kruszon-Moran D, Kit BK, et al. Trends in obesity prevalence among children and adolescents in the United States, 1988-1994 through 2013-2014. JAMA. 2016;315(21):2292-9. https:// doi.org/10.1001/jama.2016.6361.

2. Hales CM, Fryar CD, Carroll MD, Freedman DS, Ogden CL. Trends in obesity and severe obesity prevalence in US youth and adults by sex and age, 2007-2008 to 2015-2016. JAMA. 2018;319(16):1723-5. https://doi.org/10.1 001/jama.2018.3060

3. Malik VS, Popkin BM, Bray GA, Despres JP, Hu FB. Sugar-sweetened beverages, obesity, type 2 diabetes mellitus, and cardiovascular disease risk. Circulation. 2010;121(11):1356-64. https://doi.org/10.1161/CIRCULATIONA HA.109.876185.

4. Rosinger A, Herrick K, Gahche J, Park S. Sugar-sweetened beverage consumption among U.S. youth, 2011-2014. NCHS Data Brief. 2017;271:1-8.

5. Mendez MA, Miles DR, Poti JM, Sotres-Alvarez D, Popkin BM. Persistent disparities over time in the distribution of sugar-sweetened beverage intake among children in the United States. Am J Clin Nutr. 2019;109(1):79-89.
6. Ogden CL, Fryar CD, Hales CM, Carroll MD, Aoki Y, Freedman DS. Differences in obesity prevalence by demographics and urbanization in US children and adolescents, 2013-2016. JAMA. 2018;319(23):2410-8. https://doi. org/10.1001/jama.2018.5158

7. Bleich SN, Vercammen KA, Koma JW, Li Z. Trends in beverage consumption among children and adults, 2003-2014. Obesity (Silver Spring, Md). 2018; 26(2):432-41.

8. Taveras EM, Gillman MW, Kleinman K, Rich-Edwards JW, Rifas-Shiman SL. Racial/ethnic differences in early-life risk factors for childhood obesity. Pediatrics. 2010;125(4):686-95. https://doi.org/10.1542/peds.2009-2100.

9. Dodd AH, Briefel R, Cabili C, Wilson A, Crepinsek MK. Disparities in consumption of sugar-sweetened and other beverages by race/ethnicity and obesity status among United States schoolchildren. J Nutr Educ Behav. 2013;45(3):240-9. https://doi.org/10.1016/j.jneb.2012.11.005.

10. Grimes CA, Riddell $L J$, Campbell KJ, Nowson CA. Dietary salt intake, sugarsweetened beverage consumption, and obesity risk. Pediatrics. 2013;131(1): 14-21. https://doi.org/10.1542/peds.2012-1628.

11. Hu FB, Malik VS. Sugar-sweetened beverages and risk of obesity and type 2 diabetes: epidemiologic evidence. Physiol Behav. 2010;100(1):47-54. https:// doi.org/10.1016/j.physbeh.2010.01.036.

12. Briefel RR, Wilson A, Cabili C, Hedley Dodd A. Reducing calories and added sugars by improving children's beverage choices. J Acad Nutr Diet. 2013; 113(2):269-75. https://doi.org/10.1016/j.jand.2012.10.016.

13. Malik VS, Hu FB. Sugar-sweetened beverages and health: where does the evidence stand? Am J Clin Nutr. 2011;94(5):1161-2. https://doi.org/10.3945/a jen.111.025676.

14. Ludwig DS, Peterson KE, Gortmaker SL. Relation between consumption of sugar-sweetened drinks and childhood obesity: a prospective, observational analysis. Lancet. 2001;357(9255):505-8. https://doi.org/10.1016/S0140-673 6(00)04041-1.

15. Harrington S. The role of sugar-sweetened beverage consumption in adolescent obesity: a review of the literature. J Sch Nurs. 2008;24(1):3-12. https://doi.org/10.1177/10598405080240010201.

16. Millstein RA, Sallis JF. Youth advocacy for obesity prevention: the next wave of social change for health. Transl Behav Med. 2011;1(3):497-505. https://doi. org/10.1007/s13142-011-0060-0.

17. Zimmerman MA, Eisman AB, Reischl TM, Morrel-Samuels S, Stoddard S, Miller $\mathrm{AL}$, et al. Youth empowerment solutions: evaluation of an after-school program to engage middle school students in community change. Health Educ Behav. 2018;45(1):20-31. https://doi.org/10.1177/1090198117710491.

18. Martinez LS, Ndulue U, Peréa FC. Nuestro furturo saludable: connecting public health research and community development in partnership to build a healthy environment. Community Dev. 2011;42(2):255-67. https://doi. org/10.1080/15575330.2011.558206.

19. Sprague Martinez LS, Reich AJ, Flores C, Ndulue UJ, Brugge D, Gute DM et al. Critical discourse, applied inquiry and public health action with urban middle school students: lessons learned engaging youth in critical servicelearning. J Community Pract. 2017;25(1):68-89. https://doi.org/10.1080/1 0705422.2016.1269251.

20. Muturi N, Kidd T, Daniels AM, Kattelmann KK, Khan T, Lindshield E, et al. Examining the role of youth empowerment in preventing adolescence obesity in low-income communities. J Adolesc. 2018;68:242-51. https://doi. org/10.1016/j.adolescence.2018.08.001.

21. Jurkowski JM, Lawson HA, Green Mills LL, Wilner PG 3rd, Davison KK. The empowerment of low-income parents engaged in a childhood obesity intervention. Fam Community Health. 2014;37(2):104-18. https://doi.org/10.1 097/FCH.0000000000000024

22. Lewis RK, Lee FA, Brown KK, LoCurto J, Stowell D, Maryman J, et al. Youth empowerment implementation project evaluation results: a program designed to improve the health and well-being of low-income AfricanAmerican adolescents. J Prev Interv Community. 2018;46(1):28-42. https:// doi.org/10.1080/10852352.2018.1385954.

23. Hoying J, Melnyk BM. COPE: a pilot study with urban-dwelling minority sixth-grade youth to improve physical activity and mental health outcomes. J Sch Nurs. 2016;32(5):347-56. https://doi.org/10.1177/1059840516635713.

24. Melnyk BM, Jacobson D, Kelly SA, Belyea MJ, Shaibi GQ, Small L, et al. Twelve-month effects of the COPE healthy lifestyles TEEN program on overweight and depressive symptoms in high school adolescents. J Sch Health. 2015:85(12):861-70. https://doi.org/10.1111/josh.12342.

25. Wexler L, Gubrium A, Griffin M, DiFulvio G. Promoting positive youth development and highlighting reasons for living in Northwest Alaska 
through digital storytelling. Health Promot Pract. 2013;14(4):617-23. https:// doi.org/10.1177/1524839912462390.

26. Rogers EA, Fine SC, Handley MA, Davis HB, Kass J, Schillinger D. Engaging minority youth in diabetes prevention efforts through a participatory, spoken-word social marketing campaign. Am J Health Promot. 2017;31(4): 336-9. https://doi.org/10.4278/ajhp.141215-ARB-624.

27. Rushing SNC, Hildebrandt NL, Grimes CJ, Rowsell AJ, Christensen BC, Lambert WE. Healthy \& Empowered Youth: A Positive Youth Development Program for Native Youth. Am J Prev Med. 2017;52(3S3):S263-7.

28. Sprague Martinez L, Reich AJ, Flores CA, Ndulue UJ, Brugge D, Gute DM, et al. Critical discourse, Applied Inquiry and Public Health Action with Urban Middle School Students: Lessons Learned Engaging Youth in Critical Service Learning. J Community Pract. 2017;25(1):68-89.

29. Luque JS, Rivers BM, Gwede CK, Kambon M, Green BL, Meade CD. Barbershop communications on prostate Cancer screening using barber health advisers. Am J Mens Health. 2011;5(2):129-39. https://doi.org/10.11 77/1557988310365167.

30. Sprague Martinez L, Bowers E, Reich AJ, Ndulue UJ, Le AA, Peréa FC. Engaging youth of color in applied science education and public health promotion. Int J Sci Educ. 2016;38(4):688-99. https://doi.org/10.1080/ 09500693.2015.1134850.

31. Ockene IS, Tellez TL, Rosal MC, Reed GW, Mordes J, Merriam PA, et al. Outcomes of a Latino community-based intervention for the prevention of diabetes: the Lawrence Latino diabetes prevention project. Am J Public Health. 2012;102(2):336-42. https://doi.org/10.2105/AJPH.2011.300357.

32. Houston TK, Allison JJ, Sussman M, Horn W, Holt CL, Trobaugh J, et al. Culturally appropriate storytelling to improve blood pressure: a randomized trial. Ann Intern Med. 2011;154(2):77-84. https://doi.org/10.7326/0003-4819-1 54-2-201101180-00004.

33. Rosal MC, Ockene IS, Restrepo A, White MJ, Borg A, Olendzki B, et al. Randomized trial of a literacy-sensitive, culturally tailored diabetes selfmanagement intervention for low-income latinos: latinos en control. Diabetes Care. 2011;34(4):838-44. https://doi.org/10.2337/dc10-1981.

34. Rosal MC, Olendzki B, Reed GW, Gumieniak O, Scavron J, Ockene I. Diabetes self-management among low-income Spanish-speaking patients: a pilot study. Ann Behav Med. 2005;29(3):225-35. https://doi.org/10.1207/s15324 796abm2903_9.

35. Perry CL, Bishop DB, Taylor G, Murray DM, Mays RW, Dudovitz BS, et al. Changing fruit and vegetable consumption among children: the 5-a-Day power plus program in St. Paul, Minnesota. Am J Public Health. 1998;88(4): 603-9. https://doi.org/10.2105/AJPH.88.4.603.

36. Wang ML, Otis M, Rosal MC, Griecci CF, Lemon SC. Reducing sugary drink intake through youth empowerment: results from a pilot-site randomized study. Int J Behav Nutr Phys Act. 2019;16(1):58. https://doi.org/10.1186/s12 966-019-0819-0.

37. Wang ML, Lemon SC, Clausen K, Whyte J, Rosal MC. Design and methods for a community-based intervention to reduce sugar-sweetened beverage consumption among youth: H2GO! Study. BMC Public Health. 2016;16(1): 1150. https://doi.org/10.1186/s12889-016-3803-5.

38. Zimmerman MA, Empowerment theory. In: Rappaport J, Seidman E, editors. Handbook of Community Psychology. U.S.: Springer; 2000. p. 43-63.

39. Wong NT, Zimmerman MA, Parker EA. A typology of youth participation and empowerment for child and adolescent health promotion. Am J Community Psychol. 2010;46(1-2):100-14. https://doi.org/10.1007/s10464-01 0-9330-0.

40. Piaget J. The stages of the intellectual development of the child. Bull Menn Clin. 1962;26:120-8.

41. 2017 Annual Report. https://www.bgca.org/about-us/annual-report.

42. America. BaGCo: Measuring the Impact of Boys and Girls Clubs: 2017 Youth Outcomes Report. Atlanta; 2017.

43. Biesbrock AR, Walters PA, Bartizek RD. Initial impact of a national dental education program on the oral health and dental knowledge of children. J Contemp Dent Pract. 2003;4(2):1-10. https://doi.org/10.5005/jcdp-4-2-1.

44. Biesbrock AR, Walters PA, Bartizek RD. Short-term impact of a national dental education program on children's oral health and knowledge. J Clin Dent. 2004;15(4):93-7.

45. Smith TM, Talley B, Hubbard M, Winn C. Evaluation of a tobacco prevention program for children: ToPIC. J Community Health Nurs. 2008;25(4):218-28. https://doi.org/10.1080/07370010802421210.

46. Kaltreider DL, St Pierre TL. Beyond the schools: strategies for implementing successful drug prevention programs in community youth-serving organizations. J Drug Educ. 1995;25(3):223-37. https://doi.org/10.2190/5UBAXFJ0-1WEC-3VK3.

47. St Pierre TL, Kaltreider DL, Mark MM, Aikin KJ. Drug prevention in a community setting: a longitudinal study of the relative effectiveness of a three-year primary prevention program in boys \& girls clubs across the nation. Am J Community Psychol. 1992;20(6):673-706. https://doi.org/10.1 007/BF01312603.

48. Baker AD, Gilley J, James J. Kimani M: "high five to healthy living": a health intervention program for youth at an inner city community center. J Community Health. 2012;37(1):1-9. https://doi.org/10.1007/s10900-011-93 87-1.

49. Gant LM, Shimshock K, Allen-Meares P, Smith L, Miller P, Hollingsworth LA, et al. Effects of Photovoice: civic engagement among older youth in urban communities. J Community Pract. 2009;17(4):358-76. https://doi.org/10.1 080/10705420903300074.

50. Force USPST, Barton M. Screening for obesity in children and adolescents: US preventive services task Force recommendation statement. Pediatrics. 2010;125(2):361-7.

51. Kuczmarski RJ, Ogden CL, Guo SS, Grummer-Strawn LM, Flegal KM, Mei Z, et al. CDC growth charts for the United States: methods and development. Vital Health Stat 11. 2000;2002(246):1-190.

52. Hill CE, MacDougall CR, Riebl SK, Savla J, Hedrick VE, Davy BM. Evaluation of the Relative Validity and Test-Retest Reliability of a 15-Item Beverage Intake Questionnaire in Children and Adolescents. J Acad Nutr Diet. 2017;117(11): 1757-66 e1755.

53. Sharma S, Roberts L, Fleming S: Nutrition self-efficacy assessment: development of a questionnaire and evaluation of reliability in AfricanAmerican and Latino children. J Hum Nutr Diet. 2014;27 Suppl 2:160-6.

54. Hoelscher DM, Day RS, Kelder SH, Ward JL. Reproducibility and validity of the secondary level School-Based Nutrition Monitoring student questionnaire. J Am Diet Assoc. 2003;103(2):186-94.

55. Cleland V, Crawford D, Baur LA, Hume C, Timperio A, Salmon J. A prospective examination of children's time spent outdoors, objectively measured physical activity and overweight. Int J Obes. 2008;32(11):1685-93.

56. Kann L, McManus T, Harris WA, Shanklin SL, Flint KH, Hawkins J, Queen B, Lowry R, Olsen EO, Chyen D et al. Youth Risk Behavior Surveillance - United States, 2015. MMWR Surveill Summ. 2016;65(6):1-174.

57. Peterson NA, Lowe JB, Hughey J, Reid RJ, Zimmerman MA, Speer PW. Measuring the intrapersonal component of psychological empowerment: confirmatory factor analysis of the sociopolitical control scale. Am J Community Psychol. 2006;38(3-4):287-97.

58. Peterson NA, Peterson CH, Agre L, Christens BD, Morton CM. Measuring Youth Empowerment: Validation of a Sociopolitical Control Scale for Youth in an urban community context. J Community Psychol. 2011; 39(5):592-605.

59. Peterson NA, Powell KG, Peterson CH, Reid RJ. Testing the phrase completion response option format in a sociopolitical control scale for youth. Community Psychol Glob Perspect. 2017;3(1):57-71.

60. Hedrick VE, Savla J, Comber DL, Flack KD, Estabrooks PA, Nsiah-Kumi PA Ortmeier S, Davy BM. Development of a brief questionnaire to assess habitual beverage intake (BEVQ-15): sugar-sweetened beverages and total beverage energy intake. J Acad Nutr Diet. 2012;112(6):840-9.

61. 2010 National Youth Physical Activity and Nutrition Survey. ftp://ftp.cdc.gov/ pub/data/yrbs/nypans/2010nypans_questionnaire.pdf.

62. de Ruyter JC, Olthof MR, Seidell JC, Katan MB. A trial of sugar-free or sugarsweetened beverages and body weight in children. N Engl J Med. 2012; 367(15):1397-406. https://doi.org/10.1056/NEJMoa1203034.

63. James J, Thomas P, Cavan D, Kerr D. Preventing childhood obesity by reducing consumption of carbonated drinks: cluster randomised controlled trial. Bmj. 2004;328(7450):1237. https://doi.org/10.1136/bmj.38077.458438.EE.

64. Economos CD, Hyatt RR, Goldberg JP, Must A, Naumova EN, Collins JJ, et al. A community intervention reduces BMI z-score in children: Shape Up Somerville first year results. Obesity (Silver Spring, Md). 2007;15(5):1325-36.

65. Taveras EM, Perkins M, Anand S, Woo Baidal JA, Nelson CC, Kamdar N, et al. Clinical effectiveness of the massachusetts childhood obesity research demonstration initiative among low-income children. Obesity (Silver Spring, Md). 2017;25(7):1159-66.

66. Shackleton N, Hale D, Bonell C, Viner RM. Intraclass correlation values for adolescent health outcomes in secondary schools in 21 European countries. SSM Popul Health. 2016:2:217-25. https://doi.org/10.1016/j. ssmph.2016.03.005. 
67. Masood M, Reidpath DD. Intraclass correlation and design effect in BMI, physical activity and diet: a cross-sectional study of 56 countries. BMJ Open. 2016;6(1):e008173. https://doi.org/10.1136/bmjopen-2015-008173.

68. Evans CR, Lippert AM, Subramanian SV. The persistent clustering of adult body mass index by school attended in adolescence. J Epidemiol Community Health. 2016;70(3):260-3. https://doi.org/10.1136/jech-2015-2 05833.

\section{Publisher's Note}

Springer Nature remains neutral with regard to jurisdictional claims in published maps and institutional affiliations.

Ready to submit your research? Choose BMC and benefit from:

- fast, convenient online submission

- thorough peer review by experienced researchers in your field

- rapid publication on acceptance

- support for research data, including large and complex data types

- gold Open Access which fosters wider collaboration and increased citations

- maximum visibility for your research: over $100 \mathrm{M}$ website views per year

At $\mathrm{BMC}$, research is always in progress.

Learn more biomedcentral.com/submissions 